\title{
Polio Eradication Efforts in Nepal
}

\section{Suvedi BK ${ }^{1}$}

${ }^{1}$ Dr. BK Suvedi. MA, MD, MPH

Address for Correspondence: Dr. B. K. Suvedi. P. O. Box 2323, GPO Kathmandu, Nepal.

E-mail: bksubedi@healthnet.org.np

\begin{abstract}
Nepal has made tremendous effort for polio eradication. The efforts are based on the global polio eradication strategies. Despite all the efforts as per the global strategies, wild poliovirus is still present in the country. The importance of water, hygiene and sanitation is stressed as an additional strategy in still persisting areas.
\end{abstract}

Key words: Poliomyelitis, Eradication, Nepal, Immunization, Surveillance.

\section{Introduction}

Poliomyelitis at one time occurred throughout the world and now it has been limited to few countries in an "epidemic" form in 4 countries considered as "historically low". The causative organism of poliomyelitis is poliovirus with three sub-types. In 1985 World Health Organization (WHO) estimated that every year some 350,000 cases of Poliomyelitis occurred in the world.

As the known reservoir of the poliovirus are human beings, and the mode of transmission is person-to-person through fecal-oral route, and an effective vaccine is available, technically, it was considered a eradicable disease and so lots of effort has been put into it by various partners with a goal to eradicate polio by 2000 initially and postponed till 2005 later on. However, till date it has not been eradicated.

\section{Global Initiative and Nepal}

Nepal endorsed the decisions of World Health Assembly held in 1988 and was the signatory of the Polio Eradication Initiative (PEI). World Health Organization (WHO) initiated the polio eradication campaign after observing the success and experience in the United States and Latin American countries. For this purpose, WHO adopted four strategies for polio eradication, namely high routine immunization coverage, conduction of supplementary immunization days, high quality surveillance and mopping up activities. These four strategies have been considered as the pillars of the Polio eradication program.

\section{Responses of Nepal on Polio Eradication Goal}

Nepal responded to the global call for polio eradication and started implementing the strategies gradually, almost in a phase-wise manner. The following paragraphs show the implementation of strategies for polio eradication.

\section{Strategy 1: Maintain High Immunization Coverage}

Among the four strategies of polio eradication initiative, high coverage of vaccination in routine immunization is considered the most important and consequently the first strategy. Nepal introduced polio vaccine in the routine immunization program in 1981. However, countrywide expansion of the program was possible only in 1989, when the country was prepared for "universal childhood immunization". However, efforts were put into action to have high immunization coverage in subsequent years. Following table 1 shows coverage of vaccination for third dose of oral polio vaccine in Nepal.
Table 1: Immunization Coverage for Oral Polio Vaccine (third dose)

\begin{tabular}{|l|c|l|}
\hline Fiscal Year & $\begin{array}{c}\text { Coverage (\% of targeted } \\
\text { number) }\end{array}$ & \\
\hline $1996 / 97$ & 80.6 & \\
\hline $1997 / 98$ & 82.6 & \\
\hline $1998 / 99$ & 76.1 & \\
\hline $1999 / 2000$ & 80.2 & \\
\hline $2000 / 2001$ & 80.0 & \\
\hline $2001 / 2002$ & 80.3 & \\
\hline $2002 / 2003$ & 84.0 & \\
\hline $2003 / 2004$ & 90.2 & \\
\hline $2004 / 2005$ & 83.0 & \\
\hline
\end{tabular}

Source: Annual Reports, DOHS, Nepal ${ }^{4}$

As the table 1 shows, the vaccination coverage for third dose of oral polio vaccine exceeds $80 \%$ at a national scale, which is required to maintain, "herd immunity" in the community. However, there might be pockets of "low coverage" in the high coverage districts masking the unimmunized children. Similarly, few districts have low vaccination coverage rate (less than $60 \%$ ), which makes the children susceptible to wild poliovirus.

\section{Strategy 2: Supplementary Immunization Activities}

Supplementary immunization Activities (SIA) were designed to cover those children who did not get polio vaccine during the routine immunization and/or to those who might have not developed immunity against the polio virus. To provide adequate doses of vaccines to children less than five years of age, a campaign commonly termed National Immunization Days (NID) was initiated in many parts of the world. Nepal also initiated such an initiative in 1996. Every year two rounds of "immunization campaign" were conducted during winter season during the low -transmission season. About 4 million children under the age of five were targeted during the campaign. Besides the NIDs, Sub-National Immunization Days (SNIDs) were conducted in "high-risk" districts. Pre-emptive Mopping up and Mopping-up activities were also conducted in response to finding of some suspected and/or confirmed polio cases. Basically these districts were Terai districts, bordering with India and Kathmandu Valley. 
Table 2: Ratio of children receiving Oral Polio Vaccine during NIDs in different years.

\begin{tabular}{|l|c|c|c|}
\hline Year & $\begin{array}{c}\text { Number } \\
\text { of targeted } \\
\text { Children }\end{array}$ & $\begin{array}{c}\text { Coverage \% } \\
\text { (Round 1) }\end{array}$ & $\begin{array}{c}\text { Coverage \% } \\
\text { (Round 2) }\end{array}$ \\
\hline $1996 / 97$ & 3232235 & 117 & 121 \\
\hline $1997 / 98$ & 3909229 & 99 & 100 \\
\hline $1998 / 99$ & 3860983 & 94 & 97 \\
\hline $1999 / 2000$ & 3849325 & 94 & 99 \\
\hline $2000 / 2001$ & 4116889 & 99 & 101 \\
\hline $2001 / 2002$ & 4116889 & 99 & 100 \\
\hline $2002 / 2003$ & 4144464 & 102 & 103 \\
\hline $2003 / 2004$ & 4252959 & 99 & 99 \\
\hline
\end{tabular}

Table 2 above shows that the National Immunization Days were conducted successfully in Nepal with a coverage of more than $95 \%$ building theoretically an immunological barrier among the children against polio virus. Few SubNational Immunization days (SNID) were also conducted in the high-risk for Polio transmission area (not shown here) with high (95\%) vaccination coverage.

As the Regional Technical Consultative Group (TCG) of World Health Organization, South East Region (SEARO) in 2003 decided not to conduct NIDs in Nepal, NIDs were stopped in 2004. However, Mopping-up activities were continued as deemed necessary.

\section{Strategy 3: Active Surveillance}

Surveillance for wild poliovirus is third strategy adopted by WHO for polio eradication initiative. For this purpose, all children under 15 years of age, who develop limping (acute flaccid paralysis, in short, AFP) are to be investigated thoroughly and two stool specimens collected for the detection of wild polio virus for genotyping.

An institution, named "Polio Eradication Nepal (PEN)" was established in 1998 under the World Health Organization to support the Polio eradication activities in Nepal. PEN was basically providing support to the Immunization Section under the Child Health Division of Department of Health Services. The main objective of PEN was to help in surveillance activities especially for polio. Stool samples were collected from each suspected polio (Acute Flaccid Paralysis) case
Table 3: AFP cases and Laboratory Confirmed Polio Cases

\begin{tabular}{|c|c|c|c|c|}
\hline Year & $\begin{array}{l}\text { Total } \\
\text { AFP } \\
\text { cases }\end{array}$ & $\begin{array}{c}\text { Lab } \\
\text { Confirmed } \\
\text { wild Polio } \\
\text { cases }\end{array}$ & $\begin{array}{l}\text { Districts, where } \\
\text { wild polio virus } \\
\text { was detected }\end{array}$ & $\begin{array}{c}\text { Type of } \\
\text { WPV }\end{array}$ \\
\hline 1998 & 69 & 0 & - & - \\
\hline 1999 & 234 & 2 & Banke, Saptari & Type 1 \\
\hline 2000 & 211 & 4 & $\begin{array}{c}\text { Rautahat, } \\
\text { Mahottari, Dha- } \\
\text { nusha, Siraha }\end{array}$ & Type 3 \\
\hline 2001 & 186 & 0 & - & \\
\hline 2002 & 197 & 0 & - & \\
\hline 2003 & 192 & 0 & - & \\
\hline 2004 & 214 & 0 & - & \\
\hline 2005 & 230 & 4 & $\begin{array}{c}\text { Rautahat, } \\
\text { Sarlahi }\end{array}$ & Type 1 \\
\hline 2006 & 363 & 5 & $\begin{array}{c}\text { Dailekh, } \\
\text { Rautahat, Parsa, } \\
\text { Kapilbastu }\end{array}$ & Type 1 \\
\hline
\end{tabular}

across the country. In 2005, the name of PEN has been changed to WHO-Immunization Preventable diseases (WHO-IPD) as it also incorporates surveillance of measles, Japanese Encephalitis as well as the AFP. The following table shows the data on AFP cases and polio cases.

As seen from the table above, after five years of conducting national immunization days, the Wild Poliovirus was not recorded for about four years in Nepal. There was a period in the epidemic. However, it seems that, when the NID were stopped, the polio cases reappeared. Almost all the districts, where wild polio virus is detected are bordering with Northern Indian states. The re-appearance of Wild Poliovirus definitely has made Nepal into a challenging situation in terms of polio eradication. Anecdotally, all the "cases" have got number of oral polio vaccine doses, consequently, having "loss of faith" towards the oral polio vaccine, except in cases where the patient has been older than 15 years.

From programmatic perspective, indicators of "quality surveillance" for AFP have been determined by WHO. Nepal has kept these indicators at an acceptable level indicating that the efforts are adequate for PEI.

Table 4 : Surveillance Indicators of Polio Eradication Efforts in Nepal

\begin{tabular}{|l|c|c|c|c|c|c|c|c|c|}
\hline Indicators & $\mathbf{1 9 9 8}$ & $\mathbf{1 9 9 9}$ & $\mathbf{2 0 0 0}$ & $\mathbf{2 0 0 1}$ & $\mathbf{2 0 0 2}$ & $\mathbf{2 0 0 3}$ & $\mathbf{2 0 0 4}$ & $\mathbf{2 0 0 5}$ & $\mathbf{2 0 0 6}$ \\
\hline Total weekly “zero" reporting units & - & 167 & 240 & 303 & 312 & 378 & 414 & 411 & 413 \\
\hline Total active surveillance sites & - & 47 & 47 & 81 & 76 & 79 & 81 & 82 & 73 \\
\hline Total number of AFP cases reported & 69 & 234 & 211 & 186 & 197 & 192 & 213 & 230 & 363 \\
\hline $\begin{array}{l}\text { Non-polio AFP rate (Expected rate: 1 per 100,000 } \\
\text { children under 15 years of age) }\end{array}$ & 0.41 & 2.00 & 1.96 & 1.95 & 2.00 & 1.90 & 1.99 & 2.25 & 3.5 \\
\hline $\begin{array}{l}\text { Percentage of two stool collections within 14 days of } \\
\text { onset of paralysis from AFP cases }\end{array}$ & 35 & 76 & 79 & 83 & 87 & 86 & 85 & 84 & 86 \\
\hline
\end{tabular}

Source: WHO-IPD3, 2007 
The table above shows that though the Surveillance (program) indicators are encouraging for polio eradication in Nepal. Non-Polio AFP rate and Adequate stool collection are as prescribed by WHO. However, detection of Wild Polio Virus (WPV) has been increasing in last two years after a gap of four years.

\section{Strategy 4: Mopping Up Activities}

A series of mopping up activities in limited areas were carried out in Nepal in response to detection of wild polio virus in the country as well as across the geographical proximity in the southern border. Recently monovalent oral polio (m-OPV) vaccine has been introduced for mopping up activities with an expansion of the m-OPV in sub-national immunization days as well.

\section{Current Issues}

Major issues regarding the polio eradication are still the "complete implementation" of all the polio eradication strategies. High immunization coverage in itself shows promise; however, it should be critically looked economically in a long-term perspective. National Immunization days and mopping up activities are very much "short-term" strategies in term of prevention of transmission, though it might build a "immunologic barrier" among the children.

Annual report of WHO, Rotary International, CDC and UNICEF has shown that Nepal is in the category of high Risk Country for Polio transmission. It also shows that Indian states of Uttar Pradesh and Bihar are labelled as "remaining endemic states". Nepal borders with the same states. So, epidemiologically, there is every chance that there will be "importation" of cases, if indigenous transmission can be ruled out.

\section{Missed Opportunities}

The first and foremost thing to be considered in disease transmission is water, sanitation and hygiene ( $\mathrm{WaSH})$. The basic principle of prevention of any infection transmitted through oral- faecal route is to improve hygiene and sanitation. Same principle might apply to wild polio virus transmission. However, it is a neglected part in the global strategy from program perspective. The areas where polio has reappeared are in a very poor state of hygiene and sanitation. So, only creating an "immunological border" might not be adequate to "eradicate" polio with such a high cost.

\section{Conclusion}

a) Routine immunization coverage along with Special Immunization Activities and mopping up activities has shown promise for eradication of polio.

b) Wild Polio virus type 2 and 3 seem to have disappeared as type 2 has not been detected at all after the surveillance began and type 3 after 2000 .

c) Wild Poliovirus type 1 is still present in Nepal (though in a form of "importation"). It is persistent across the border in "epidemic" proportion with every potential to enter Nepal. d) AFP surveillance is of international standard and able to pick up all the "suspected" cases for laboratory investigation.

e) Water, sanitation and Hygiene has been a neglected area for polio eradication though it is an established fact that polio is transmitted through fecal-oral route and so it needs high attention in areas where polio is still persisting despite high routine immunization coverage.

\section{Recommendation}

Keeping in view the persisting wild polio virus and the efforts along with the high cost of it, it is important that the following steps be taken into consideration.

1) Provide serious attention to the water, sanitation and hygiene in the epidemic areas as the polio virus is transmitted through faecal-oral route.

2) Continue with special immunization activities.

3) Continue with quality surveillance activities.

Nepal might be able to eradicate wild polio virus within few years given that across the southern border the epidemic is "controlled and eradicated".

\section{Acknowledgement}

I would like to acknowledge the National Immunization Program of Nepal and the WHO-IPD team for their effort to make Nepal Polio-free.

\section{References}

1. WHO, Rotary International, CDC and UNICEF. 2006. Global Polio Eradication Initiative. Annual Report 2006. Annual Report.

2. John TJ, Shah NK and Thacker N. 2006. Indian Academy of Pediatrics and Polio Eradication in India. Indian Pediatrics. Volume 47, September 2006.

3. WHO-IPD. Polio Eradication Newsletters. 2006.

4. Department of Health Services, Nepal. Annual reports. 2003/4, 2004/5.

5. WHO-SEARO. EPI Fact Sheet, IVD. 14 Jun 2007

6. Suvedi BK. 2004. Surveillance of Vaccine Preventable Diseases in Nepal. 